\title{
TEORIA DOS DIREITOS FUNDAMENTAIS: PRIMEIRAS REFLEXÕES
}

\author{
Gustavo Vinícius Camin* \\ Zulmar Fachin**
}

SUMÁRIO: Introdução; 1.1 Conceito; 2 Características; 2.1 Historicidade; 2.2 Universalidade; 2.3 Inalienabilidade; 2.4 Imprescritibilidade; 2.5 Vinculatividade; 2.6 Indivisibilidade; 3 Gerações ou Dimensões de Direitos Fundamentais; 3.1 Direitos Fundamentais de Primeira Dimensão; 3.2 Direitos Fundamentais de Segunda Dimensão; 3.3 Direitos Fundamentais de Terceira Geração; 3.4 Direitos Fundamentais de Quarta Dimensão; 3.5 Direitos Fundamentais de Quinta Dimensão; 3.6Direitos Fundamentais de Sexta Dimensão; 4 Conclusão; Referências.

RESUMO: O objetivo da pesquisa é refletir sobre a teoria dos direitos fundamentais. Considera, então, o conceito, as características e as dimensões desses direitos. No decorrer das décadas de 1960 e 1970, Norberto Bobbio falava na era dos direitos. No alvorecer do século XXI, podemos falar na era dos direitos fundamentais. Desse modo, os direitos fundamentais passaram a assumir extraordinária importância. Esse destaque não se verifica apenas na sua dimensão teórica, mas inclusive no campo prático, visto que tais direitos precisam ser efetivados em benefício das pessoas.

PALAVRAS-CHAVE: Características; Dimensões; Direitos Fundamentais.

\section{THE THEORY OF FUNDAMENTAL RIGHTS: SOME REFLECTIONS}

ABSTRACT: Current research discusses the theory of Fundamental Rights and analyzes their concept, characteristics and dimensions. During the 1960s and 1970s, Norberto Bobbio referred to the era of rights. In the early $21^{\text {st }}$ century, we may be discussing the era of fundamental rights since fundamental rights have been elevated to extraordinary importance. This importance does not lie merely on the theoretical basis but specifically in practice, since these rights have to be efficacious for the benefit of the human person.

KEY WORDS: Characteristics; Dimensions; Fundamental Rights.

\footnotetext{
Discente do Programa de Pós-Graduação Stricto sensu em Ciências Jurídicas do Centro Universitário de Maringá - UNICESUMAR; Especialista em Direito do Estado pela Universidade Estadual de Londrina (UEL); Especialista em Direito Aplicado pela Escola da Magistratura do Paraná (EMAP); Procurador do Município de Maringá (PR); Advogado; E-mail: adv.camin@hotmail.com

${ }^{*}$ Doutor emDireitoConstitucional pela Universidade Federal do Paraná (UFPR); Docente no Programa de Pósgraduação Strico Sensu em Ciência Jurídica no Centro Universitário de Maringá (UNICESUMAR), Maringá (PR) e na Universidade Estadual de Londrina (UEL), Londrina (PR); Presidente do Instituto de Direito Constitucional e Cidadania (IDCC).
} 


\section{TEORÍA DE LOS DERECHOS FUNDAMENTALES: PRIMERAS REFLEXIONES}

RESUMEN: El objetivo de la investigación es reflexionar sobre la teoría de los derechos fundamentales. Considera, entonces, el concepto, las características y las dimensiones de esos derechos. En el transcurso de las décadas de 1960 y 1970, Norberto Bobbio hablaba de la era de los derechos. En el arborecer del siglo XXI, podemos hablar de la era de los derechos fundamentales. De este modo, los derechos fundamentales asumieron una extraordinaria importancia. Ese destaque no se verifica solo en su dimensión teórica, pero también en el campo práctico, ya que tales derechos necesitan ser efectuados en beneficio de las personas.

PALABRAS-CLAVE: Características; Dimensiones, Derechos Fundamentales.

\section{INTRODUÇÃO}

Com o término da Segunda Guerra Mundial, nasceu a consciência de que era preciso proteger os direitos fundamentais da pessoa humana. Foram aprovados muitos tratados internacionais cuja temática central era tais direitos. Por outro lado, as Constituições dos países, aprovadas após o encerramento do grande conflito, dedicaram atenção especial não apenas à proteção, mas também à efetivação dos direitos fundamentais.

Nesse contexto, a Constituição brasileira, promulgada em 05 de outubro de 1988, previu amplo rol de direitos fundamentais, verdadeira teia normativa destinada a proteger o núcleo essencial da pessoa humana. No mesmo sentido, inclusive com fundamento na própria Constituição, desenvolveu-se ampla doutrina especializada em compreender os direitos fundamentais, de tal modo que esses direitos foram alçados a um plano de destaque.

Neste sentido, tornou-se importante refletir sobre as características dos direitos fundamentais, bem como identificar as dimensões desses direitos. E s s e tema tem merecido a atenção especial dos pesquisadores não apenas da área do Direito, mas também de outros campos do saber, tais como a Filosofia, a Sociologia, a Antropologia, a Teoria do Estado. 


\subsection{CONCEITO}

O primeiro passo para a compreensão do tema é identificar o conceito de direitos fundamentais. Neste sentido, diversos autores elaboraram conceitos que levam à reflexão. Para Jorge Miranda,

os direitos ou as posições jurídicas subjectivas das pessoas enquanto tais, individual ou institucionalmente consideradas, assentes na Constituição, seja na Constituição formal, seja na Constituição material - donde, direitos fundamentais em sentido formal e direitos fundamentais em sentido material. ${ }^{1}$

Ingo Sarlett, um dos principais teóricos brasileiros que mais se dedicou ao estudo dos direitos fundamentais, afirma que

todas aquelas posições jurídicas concernentes as pessoas, que, do ponto de vista do direito constitucional positivo, foram, por seu conteúdo e importância (fundamentalidade em sentido material), integradas ao texto constitucional e, portanto, retiradas da esfera de disponibilidade dos poderes constituídos (fundamentalidade formal), bem como as que, por seu conteúdo e significado, possam lhe ser equiparadas, agregando-se à Constituição material, tendo, ou não, assento na Constituição formal (aqui considerada a abertura material do catálogo). ${ }^{2}$

Desta forma, direitos fundamentais demonstram ser aqueles direitos que constitucionalmente são elencados como fundamentais, e que ainda, por sua essência, preenchem toda a plenitude e profundidade de seu sujeito.

Pode-se mencionar, ainda, a contribuição de Luiz Alberto David Araujo. Este autor afirma que

Os direitos fundamentais podem ser conceituados como a categoria jurídica instituída com a finalidade de proteger a dignidade humana em todas as dimensões. Por isso, tal qual o ser humano, tem natureza polifacética, buscando resguardar o homem na sua liberdade (direitos individuais), nas suas necessidades (direitos sociais, econômicos e culturais) e na sua preservação (direitos relacionados à fraternidade e à solidariedade) ${ }^{3}$

\footnotetext{
${ }^{1}$ MIRANDA, Jorge. Manual de direito constitucional. Coimbra: Coimbra, 1998, p.7.

2 SARLET, Ingo Wolfgang. A eficácia dos direitos fundamentais. Porto Alegre: Livraria do Advogado, 1998, p. 80.

3 ARAUJO, Luiz Alberto David; NUNES JÚNIOR, Vidal Serrano. Curso de direito constitucional. 9. ed. São Paulo: Saraiva, 2005, p. 109-110.
} 
Fica claro, portanto, que os direitos fundamentais são aqueles direitos necessários para impor ao Estado limites em sua atuação, bem como os que atribuem às pessoas a prerrogativa de exigir do Estado atuação positiva para efetivá-los.

\section{CARACTERÍSTICAS}

\subsection{HISTORICIDADE}

Os direitos fundamentais são o resultado de uma longa evolução histórica. Foram surgindo em circunstâncias definidas no tempo e em razão de necessidades fundamentais das pessoas.

Observa Norberto Bobbio que,

os direitos do homem, por mais fundamentais que sejam, são direitos históricos, ou seja, nascidos em certas circunstâncias, caracterizadas por lutas em defesa de novas liberdades contra velhos poderes, e nascidos de modo gradual, não todos de uma vez e nem de uma vez por todas.

[...] o que parece fundamental numa época histórica e numa determinada civilização não é fundamental em outras épocas e em outras culturas. $^{4}$

Pode-se entender assim que a historicidade demonstra que os direitos fundamentais evoluem com o passar do tempo. Sendo assim, o direito que não era fundamental em um determinado momento histórico, em outro pode vir a ser considerado como tal.

\subsection{UNIVERSALIDADE}

Os direitos fundamentais são universais na medida em que podem ser titularizados por qualquer pessoa, não importando o momento histórico o a dimensão geográfica.

Nessa perspectiva, lembra Zulmar Fachin que "os direitos fundamentais caracterizam-se pela universalidade, ou seja, são direitos que valem em todos os lugares, em todos os tempos, e são aplicáveis a todas as pessoas". 5

Denota-se assim que os direitos fundamentais são universais, podendo ser opostos contra qualquer pessoa e a qualquer tempo.

${ }_{4}^{4}$ BOBBIO, Norberto. A era dos direitos. Rio de Janeiro: Campus, 1992, p. 5-19.

5 FACHIN, Zulmar. Curso de direito constitucional. 5. ed. Rio de Janeiro: Forense, 2012, p. 236. 


\subsection{INALIENABILIDADE}

A característica da inalienabilidade é conceituada por José Afonso da Silva como: "direitos intransferíveis, inegociáveis, porque não são de conteúdo econômico-patrimonial. Se a ordem constitucional os confere a todos, deles não se pode desfazer, porque são indisponíveis" ${ }^{6}$

Assim, baseado nesta característica, os direitos fundamentais não podem ser vendidos, trocados, dados, negociados e nem mesmo transferidos a outrem por vontade de uma parte em seu favor ou a favor de outrem.

\subsection{IMPRESCRITIBILIDADE}

Pode-se afirmar que os direitos fundamentais são imprescritíveis. Pode passar o tempo que for, e sobre eles não incidem a prescrição.

A lição de José Afonso da Silva é apropriada:

O exercício de boa parte dos direitos fundamentais ocorre só no fato de existirem reconhecidos na ordem jurídica. Em relação a eles não se verificam requisitos que importem em sua prescrição. Vale dizer, nunca deixam de ser exigíveis. Pois prescrição é um instituto jurídico que somente atinge, coarctando, a exigibilidade dos direitos de caráter patrimonial, não a exigibilidade de direitos personalíssimos, ainda que não individualistas, como é o caso. Se são sempre exercíveis e exercidos, não há intercorrência temporal de não exercício que fundamente a perda da exigibilidade pela prescrição. ${ }^{7}$

Vislumbra-se que os direitos fundamentais não perdem sua exigibilidade por inércia de seu detentor, vez que tais direitos podem ser exercidos, não havendo aí qualquer lapso de tempo que possa ser demonstrado como fundamento para se poder alegar perecimento do direito.

\subsection{VINCULATIVIDADE}

Os direitos fundamentais vinculam. Portanto, não podem mais ser compreendidos como meras declarações, desprovidas de força normativa. Ao

\footnotetext{
${ }^{6}$ SILVA, José Afonso da. Curso de direito constitucional Positivo. São Paulo: Malheiros, 2011, p. 181.

7 Idem.
} 
contrário, tais direitos são dotados de normatividade, incidindo diretamente nas relações jurídicas.

Os direitos fundamentais vinculam não apenas os poderes estatais, mas também o poder privado e os indivíduos de modo geral. Daí a importância de estarem positivados na Constituição do País.

\subsection{INDIVISIBILIDADE}

Os direitos fundamentais são indivisíveis em dois aspectos: primeiro, porque um direito fundamental não pode ser cindido em seu conteúdo mínimo; em segundo, porque os direitos civis e políticos não podem ser separados dos direitos econômicos, sociais e culturais.

Sobre a indivisibilidade, Vladimir Brega Filho elucida que "a indivisibilidade dos direitos fundamentais faz com que tenhamos que tratar os direitos fundamentais das várias gerações de forma igual, pois se cuida de um mesmo gênero de direitos" ${ }^{8}$

Percebe-se, portanto, que, ao se tratar de direitos fundamentais, não se pode dividi-los, pois está a se tratar de direitos que se completam.

\section{GERAÇÕES OU DIMENSÕES DOS DIREITOS FUNDAMENTAIS}

A doutrina diverge entre o uso das expressões dimensões ou gerações de direitos fundamentais. O vocábulo gerações pode levar à ideia de sucessão, de substituição, o que resultaria em problemas de compreensão. Considerando que não existe sucessão, mas sim acréscimos de direitos fundamentais, optar-se-á, no âmbito desta pesquisa, o vocábulo dimensões. Serão tratadas, portanto, as dimensões dos direitos fundamentais.

\subsection{DIREITOS FUNDAMENTAIS DE PRIMEIRA DIMENSÃO}

Os direitos fundamentais de primeira dimensão, como a própria terminologia sugere, são os primeiros direitos que foram assegurados.

Observa Gilmar Ferreira Mendes que:

${ }^{8}$ BREGA FILHO, Vladimir. Direitos fundamentais na Constituição de 1988: conceito jurídico das expressões. São Paulo: Juarez de Oliveira, 2002, p. 62. 
A primeira delas abrange os direitos referidos nas Revoluções americana e francesa. São os primeiros a ser positivados, daí serem ditos de primeira geração. Pretendia-se, sobretudo, fixar uma esfera de autonomia pessoal refratária às expansões do Poder. Daí esses direitos traduzirem-se em postulados de abstenção dos governantes, criando obrigações de não fazer, de não intervir sobre aspectos da vida pessoal de cada indivíduo. ${ }^{9}$

Ainda, segundo Paulo Bonavides, os direitos fundamentais de primeira dimensão são:

Os direitos da primeira geração são os direitos da liberdade, os primeiros a constarem do instrumento normativo constitucional, a saber, os direitos civis e políticos, que em grande parte correspondem, por um prisma histórico, àquela fase inaugural do constitucionalismo do Ocidente. ${ }^{10}$

Ao explicar sobre o tema da primeira dimensão, salienta Luiz Alberto David Araujo:

Trata-se de direitos que representavam uma ideologia de afastamento do Estado das relações individuais e sociais. O Estado deveria ser apenas o guardião das liberdades, permanecendo longe de qualquer interferência no relacionamento social. São as chamadas 'liberdades públicas negativas' ou 'direitos negativos', pois exigem do Estado um comportamento de abstenção. ${ }^{11}$

Desta forma, verifica-se que os direitos fundamentais de primeira dimensão vieram para valorizar o homem enquanto pessoa, o homem que titulariza liberdades, o homem membro da sociedade civil. Tais liberdades - denominadas liberdades negativas - atuam como limitações ao poder estatal e de igual forma vieram como restrição ao Estado.

\subsection{DIREITOS FUNDAMENTAIS DE SEGUNDA DIMENSÃO}

Se os direitos fundamentais de primeira dimensão referem-se à liberdade, os de segunda estão vinculados à igualdade.

\footnotetext{
9 MENDES, Gilmar Ferreira; COELHO, Inocêncio Mártires; BRANCO, Paulo Gustavo G. et al. Curso de direito constitucional. São Paulo: Saraiva, 2009, p. 267.

${ }^{10}$ BONAVIDES, Paulo. Curso de direito constitucional. São Paulo: Malheiros, 2011, p. 563.

${ }^{11}$ ARAUJO; NUNES JÚNIOR, op. cit., 2005, p. 116.
} 
Assim, leciona Gilmar Ferreira Mendes:

O descaso para com os problemas sociais, que veio a caracterizar o Êtat Gendarme, associado às pressões decorrentes da industrialização em marcha, o impacto do crescimento demográfico e o agravamento das disparidades no interior da sociedade, tudo isso gerou novas reivindicações, impondo ao Estado um papel ativo na realização da justiça social. O ideal absenteísta do Estado liberal não respondia, satisfatoriamente, às exigências do momento. Uma nova compreensão do relacionamento Estado/sociedade levou os Poderes Públicos a assumir o dever de operar para que a sociedade lograsse superar as suas angústias estruturais. Daí o progressivo estabelecimento pelos Estados de seguros sociais variados, importando intervenção intensa na vida econômica e a orientação das ações estatais por objetivos de justiça social. Como conseqüência, uma diferente pletora de direitos ganhou espaço no catálogo dos direitos fundamentais - direitos que não mais correspondem a uma pretensão de abstenção do Estado, mas que o obrigam a prestações positivas. São os direitos de segunda geração, por meio dos quais se intenta estabelecer uma liberdade real e igual. ${ }^{12}$

Bonavides:

Quanto aos direitos fundamentais de segunda dimensão, preconiza Paulo

Os direitos da segunda geração merecem uma análise mais ampla. São os direitos sociais, culturais e econômicos bem como os direitos coletivos ou de coletividade, introduzidos no constitucionalismo das distintas formas de Estado social, depois que germinaram por obra da ideologia e da reflexão antiliberal do século XX. Nasceram abraçados ao princípio da igualdade, do qual não se podem separar, pois fazê-lo equivaleria a desmembrá-lo da razão de ser que os ampara e estimula. ${ }^{13}$

Vislumbra-se, assim, que diferentemente da primeira dimensão, a qual gerou direitos negativos ao Estado, ou seja, de não privar o homem de suas liberdades, a segunda dimensão criou direitos fundamentais positivos ao Estado, uma vez que os direitos sociais, culturais e econômicos exigem uma conduta positiva do Poder Público, exige que ele realize determinada tarefa.

Celso Lafer analisa as duas dimensões de direitos fundamentais:

A primeira geração de direitos viu-se igualmente complementada historicamente pelo legado do socialismo, cabe dizer,

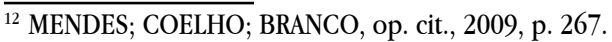

${ }^{13}$ BONAVIDES, op. cit., 2011, p. 564. 
pelas reivindicações dos desprivilegiados a um direito de participar do "bem-estar social", entendido como os bens que os homens, através de um processo coletivo, vão acumulando no tempo. É por essa razão que os assim chamados direitos de segunda geração, previstos pelo welfare state, são direitos de crédito do indivíduo em relação à coletividade. Tais direitos - como o direito ao trabalho, à saúde, à educação - têm como sujeito passivo o Estado porque, na interação entre governantes e governados, foi a coletividade que assumiu a responsabilidade de atendê-los [...] Daí a complementaridade, na perspectiva ex parte populi, entre os direitos de primeira e segunda geração, pois estes últimos buscam assegurar as condições para o pleno exercício dos primeiros, eliminando ou atenuando os impedimentos ao pleno uso das capacidades humanas. ${ }^{14}$

Assim, fica claro que a segunda dimensão não surge para tirar a eficácia ou a vigência dos direitos da primeira, mas surge para complementá-los e auxiliar no desenvolvimento do homem, devido às novas necessidades que surgiram, que fizeram tais direitos aparecerem.

\subsection{DIREITOS FUNDAMENTAIS DE TERCEIRA GERAÇÃO}

Na trajetória evolutiva, foram surgindo novos direitos fundamentais. Passouse a falar, então, na terceira dimensão.

Sobre a terceira dimensão, ensina Pietro de Jesus Lora Alarcon:

[...] a aparição dessa terceira dimensão dos direitos fundamentais evidencia uma tendência destinada a alargar a noção de sujeito de direitos e do conceito de dignidade humana, o que passa a reafirmar o caráter universal do indivíduo perante regimes políticos e ideologias que possam colocá-lo em risco, bem como perante toda uma gama de progressos tecnológicos que pautam hoje a qualidade de vida das pessoas, em termos de uso de informática, por exemplo, ou com ameaças concretas à cotidianidade da vida do ser em função de danos ao meio ambiente ou à vantagem das transnacionais e corporações que controlam a produção de bens de consumo, o que desdobra na proteção aos consumidores na atual sociedade de massas. ${ }^{15}$

\footnotetext{
${ }^{14}$ LAFER, Celso. A reconstrução dos direitos humanos: um diálogo com o pensamento de Hannah Arendt. 6. ed. São Paulo: Companhia das Letras, 2006, p. 127.

15 ALARCÓN, Pietro de Jésus Lora. O patrimônio genético humano e sua proteção na Constituição Federal de 1988. São Paulo: Método, 2004, p. 81
} 
Paulo Bonavides identificou a origem da teoria das dimensões dos direitos fundamentais, apontando o surgimento da terceira dimensão. Para ele:

A teoria, com Vask e outros, já identificou cinco direitos da fraternidade, ou seja, da terceira geração: o direito ao desenvolvimento, o direito à paz, o direito ao meio-ambiente, o direito da propriedade sobre o patrimônio comum da humanidade e o direito de comunicação. ${ }^{16}$

No mesmo sentido, é o magistério de Gilmar Ferreira Mendes. Afirma ele:

Já os direitos chamados de terceira geração peculiarizam-se pela titularidade difusa ou coletiva, uma vez que são concebidos para a proteção não do homem isoladamente, mas de coletividades, de grupos. Tem-se, aqui, o direito à paz, ao desenvolvimento, à qualidade do meio ambiente, à conservação do patrimônio histórico cultural. ${ }^{17}$

Assim, nota-se que a terceira dimensão dos direitos fundamentais abrange não só o homem como indivíduo, mas os direitos da coletividade de homens, os direitos comuns de todo o povo que habita o planeta.

\subsection{DIREITOS FUNDAMENTAIS DE QUARTA DIMENSÃO}

Boa parte da doutrina nega a existência de uma quarta dimensão de direitos fundamentais. Contudo, autores como Norberto Bobbio e Paulo Bonavides a identificam no processo evolutivo dos direitos fundamentais.

Segundo Paulo Bonavides, os direitos fundamentais de quarta dimensão são a democracia, o pluralismo e a informação. Para ele:

A democracia positivada enquanto direito da quarta geração há de ser, de necessidade, democracia direta. Materialmente possível graças aos avanços da tecnologia de comunicação, e legitimamente sustentável graças à informação correta e às aberturas pluralistas do sistema. Desse modo, há de ser também uma democracia isenta já das contaminações da mídia manipuladora, já do hermetismo de exclusão, de índole autoritária e unitarista, familiar ao monopólio do poder. Tudo isso, obviamente, se a informação e o pluralismo vingarem por igual como direitos paralelos e coadjutores da democracia; esta, porém, enquanto direito do gênero humano, projetado e concretizado no último grau de sua evolução conceitual. ${ }^{18}$

\footnotetext{
$\overline{{ }^{16} \text { BONAVIDES, op. cit., 2011, p. } 569 .}$

${ }^{17}$ MENDES; COELHO; BRANCO, op. cit., 2009, p. 268.

${ }^{18}$ BONAVIDES, op. cit., 2011, p. 571.
} 
Denota-se, assim, que, devido à globalização política, introduziu-se no âmbito jurídico os direitos fundamentais de quarta dimensão.

Norberto Bobbio, por outro lado, observa que a quarta dimensão de direitos fundamentais é composta por aqueles direitos relativos às pesquisas biológicas. Afirma que:

[...] já apresentam novas exigências que só poderiam chamarse de direitos de quarta geração, referentes aos efeitos cada vez mais traumáticos da pesquisa biológica, que permitirá manipulações do patrimônio genético de cada indivíduo. ${ }^{19}$

Percebe-se assim, nas passadas de Norberto Bobbio, que há também dentro da doutrina a quarta dimensão de direitos fundamentais que surgiu para a proteção do indivíduo decorrente dos avanços das pesquisas genéticas e da biotecnologia, o que se intitula na atualidade de biodireito.

\subsection{DIREITOS FUNDAMENTAIS DE QUINTA DIMENSÃO}

A quinta dimensão de direitos fundamentais é uma criação de Paulo Bonavides, sustentada a partir do início da primeira década de século XXI. Este autor entende que a paz (oposto da guerra) deve ser erigida como um direito fundamental a compor uma nova dimensão.

Afirma Paulo Bonavides:

Estuário de aspirações coletivas de muitos séculos, a paz é o corolário de todas as justificações em que a razão humana, sob o pálio da lei e da justiça, fundamenta o ato de reger a sociedade, de modo a punir o terrorista, julgar o criminoso de guerra, encarcerar o torturador, manter inviolável as bases do pacto social, estabelecer e conservar, por intangíveis, as regras, princípios e cláusulas da comunidade política. ${ }^{20}$

Torna-se, portanto, necessário reconhecer a existência do direito fundamental à paz, compondo, inclusive, uma nova dimensão.

\footnotetext{
${ }^{19}$ BOBBIO, op. cit., 1992, p. 6.

${ }^{20}$ BONAVIDES, op. cit., 2011, p. 590.
} 


\subsection{DIREITOS FUNDAMENTAIS DE SEXTA DIMENSÃO}

O século XXI será marcado, dentre outras coisas, pela escassez da água potável. Embora, em princípio, haja abundância desse bem essencial, sua má distribuição e a dificuldade de acesso por parte de milhões de pessoas geram a escassez. Neste sentido, sustenta-se que o acesso à água potável é um direito fundamental componente de uma nova dimensão de direitos.

Zulmar Fachin e Deise Marcelino da Silva, ao escreverem sobre o tema, salientam:

Afirma-se, agora, a existência de uma sexta dimensão de direitos fundamentais. A água potável, componente do meio ambiente ecologicamente equilibrado, exemplo de direito fundamental de terceira dimensão, merece ser destacada e alçada a um plano que justifique o nascimento de uma nova dimensão de direitos fundamentais. ${ }^{21}$

Ressaltando a importância da água potável para a sobrevivência no e do Planeta, lecionam os autores:

[...] A escassez de água potável no mundo, sua má-distribuição, seu uso desregrado e a poluição em suas mais diversas formas geraram uma grave crise, a comprometer a subsistência da vida no Planeta. Em outras palavras, a escassez de água potável é um problema crucial. Logo, essa carência gera a necessidade de novo direito fundamental. [...]."22

Conclui-se, desta forma, que os direitos fundamentais desenharam no tempo uma grande evolução. A cada momento histórico, em razão de circunstâncias definidas, foram surgindo novos direitos fundamentais, compondo este imenso acervo de direito a proteger as pessoas por todas as partes do mundo.

\footnotetext{
${ }^{21}$ FACHIN, Zulmar; SILVA, Deise Marcelino da. Acesso à água potável: direito fundamental de sexta dimensão. 2 . ed. Campinas: Millennium, 2012, p. 74.

${ }^{22}$ FACHIN; SILVA, op. cit., 2012, p. 79.
} 


\section{CONCLUSÃO}

1. Os direitos fundamentais vêm assumindo, desde os finais do século XX, elevada importância na sociedade e despertando o interesse de estudiosos e pesquisadores de diversas áreas do conhecimento humano, especialmente do Direito.

2. A doutrina desenvolveu diversas características dos direitos fundamentais, destacando-se a historicidade, a universalidade, a inalienabilidade, a imprescritibilidade, a vinculatividade e a indivisibilidade.

3. Os direitos fundamentais são o resultado de um longo processo histórico. As circunstâncias históricas, em cada momento específico, geraram direitos fundamentais, os quais foram sendo acrescidos a outros já existentes.

4. Desse modo, passou-se a falar em dimensões de direitos fundamentais. Podem-se mencionar, neste sentido, seis dimensões distintas de direitos fundamentais.

\section{REFERÊNCIAS}

ARAUJO, Luiz Alberto David; NUNES JÚNIOR, Vidal Serrano. Curso de direito constitucional. 9. ed. São Paulo: Saraiva, 2005.

BOBBIO, Norberto. A era dos direitos. 10. ed. Rio de Janeiro: Campus, 1992.

BONAVIDES, Paulo. Curso de direito constitucional. São Paulo: Malheiros, 2011.

BREGA FILHO, Vladimir. Direitos fundamentais na Constituição de 1988: conceito jurídico das expressões. São Paulo: Juarez de Oliveira, 2002.

FACHIN, Zulmar; SILVA, Deise Marcelino. Acesso à água potável: direito fundamental de sexta dimensão. 2. ed. Campinas: Millennium, 2012.

FACHIN, Zulmar. Curso de direito constitucional. 5. ed. Rio de Janeiro: Forense, 2012.

LAFER, Celso. A reconstrução dos direitos humanos: um diálogo com o pensamento de Hannah Arendt. 6. ed. São Paulo: Companhia das Letras, 2006.

MENDES, Gilmar Ferreira; COELHO, Inocêncio Mártires; BRANCO, Paulo Gustavo Gonet. Curso de direito constitucional. São Paulo: Saraiva, 2009. 
MIRANDA, Jorge. Manual de direito constitucional. Coimbra: Coimbra, 1998.

SARLET, Ingo Wolfang. A Eficácia dos direitos fundamentais. Porto Alegre: Livraria do Advogado, 1998.

SILVA, José Afonso. Curso de direito constitucional positivo. São Paulo: Malheiros, 2011.

Recebido em: 26 de janeiro de 2015 Aceito em: 26 de fevereiro de 2015 